\title{
Calibration of the Wastewater Treatment Plant Model Based on the Activated Sludge Model No. 2d - Case Study of a Municipal WWTP
}

\author{
Melinda Simon-Várhelyi ${ }^{1}$, Alexandra Veronica Luca ${ }^{1}$, Marius Adrian Brehar ${ }^{1}$, Vasile Mircea Cristea ${ }^{1}$ \\ ${ }^{1}$ Babeș-Bolyai University of Cluj-Napoca, Faculty of Chemistry and Chemical Engineering \\ 11 Arany János Street, Cluj-Napoca, Romania \\ mvarhelyi@chem.ubbcluj.ro; aluca@chem.ubbcluj.ro; breharmarius@gmail.com; mcristea@chem.ubbcluj.ro;
}

\section{Extended Abstract}

Mathematical modelling and simulation in the wastewater treatment field have gained an important role in the recent years. The most widespread used technology at the municipal wastewater treatment plants (WWTPs) is the activated sludge process. The Activated Sludge Models (ASM) No. 1, 2, 2d and 3 are the state-of-the art and they were developed for describing the complex WWTP biochemical processes $[1,2]$. The calibration of the municipal WWTP model is required for matching it to the plant particular behaviour [3]. The calibrated WWTP model becomes a useful tool for understanding the WWTP processes, developing the operation alternatives, investigating different control strategies, assessing design improvements and proposing solutions for reducing the greenhouse gases emissions. This research presents the calibration of a municipal WWTP model and it is a case study for a Romanian municipal WWTP with Anaerobic-Anoxic-Oxic $\left(\mathrm{A}^{2} \mathrm{O}\right)$ configuration.

First, the objectives of the calibration and the desired accuracy of the calibrated model were defined. In the second step, influent, effluent and operation data obtained by online instrumentation and laboratory measurements were collected from the municipal WWTP under study. Measurements for the concentration of the chemical oxygen demand (COD), total nitrogen, nitrates and nitrites, free and saline ammonia, ortho-phosphates, total suspended solids, coupled with flow rates of the influent wastewater, nitrate recirculation, return activated sludge, waste and air entering the aerobic biodegradation tanks were examined, reconciled and subsequently used for the model calibration. The construction data consisting in the volumes, areas, heights of the biodegradation tanks, secondary and primary settlers were included in the model. The calibrated municipal WWTP model is composed of a primary clarifier model, seven bioreactors (two anaerobic, two anoxic and three aerobic bioreactors described by the ASM2d) and a secondary clarifier. In the third step, the calibration was formulated as an optimization problem. The objective function to be minimized was defined as the sum of the absolute differences between the measured effluent and model predicted effluent concentration for the soluble COD, nitrates and nitrites, ammonia, phosphorus and total suspended solids. The decision variables, containing a set of influent wastewater variables (Fermentable, readily biodegradable organic substrates, Fermentation products, considered to be acetate, Inert soluble organic material, Inert particulate organic material, Heterotrophic organism), bioreactor and settler process parameters (Lysis rate constant of heterotrophs, Saturation/Inhibition coefficient for oxygen, Decay rate of autotrophic biomass, Rate constant for storage of polyhydroxyalkanoates, Anoxic hydrolysis reduction factor, Hindered zone settling settler parameter, Flocculant zone settling settler parameter and Non-settleable fraction settler parameter) were chosen based on local sensitivity analyses and their boundaries were set following the literature review. Steady state optimization was successfully performed. The calibrated influent soluble COD was obtained to be more than half of the influent total COD, while the calibrated process parameters were obtained in the range defined in the literature. The absolute and relative differences between the effluent model data and the effluent measured data were calculated for the effluent pollutant concentrations. The relative difference for nitrates and nitrites and ortho-phosphates were small $(0.5 \%)$, acceptable differences were observed in the case of soluble COD (3.6\%), ammonia and total suspended solids $(6.3 \%)$. Lastly, the calibrated model was tested in dynamic state performing simulations with measured influent and operation data varying at every 10 minutes. The modelled effluent pollutant concentration profiles approximated well the measured effluent daily variations. Matlab and Simulink software were used for simulation and optimization.

Results obtained with the calibrated model showed that the municipal WWTP model was calibrated successfully, as both the steady state and dynamic simulations sustained this conclusion. 


\section{Acknowledgement}

The authors would like to acknowledge "Compania de Apă Someș SA" for its collaboration and also the support of the Collegium Talentum 2019 Programme of Hungary.

\section{References}

[1] M. Henze, W. Gujer, T. Mino and M. van Loosdrecht, Activated sludge models ASM1, ASM2, ASM2d and ASM3. Cornwall, UK: IWA Publishing, Scientific and Technical Report series, 2002.

[2] L. Rieger, S. Gillot, G. Langergraber, T. Ohtsuki, A. Shaw, I. Takács and S. Winkler, Guidelines for Using Activated Sludge Models. London, UK: IWA Publishing, 2013.

[3] M. Várhelyi, V. M. Cristea, M. Brehar, E. D. Nemeș and A. Nair, "WWTP model calibration based on different optimization approaches," Environ. Eng. Manag. J., vol. 18, no. 8, pp. 1657-1670, 2019. 